\title{
HUNTING ANIMALS OF THE BUKHARA REGION AND ISSUES
}

OF THEIR RATIONAL USE

Doctor of biological sciences-Kholboev F.R. ${ }^{\text {a }}$

Researcher-Shodieva F.O. ${ }^{b}$

Mirkhonova Z.P. ${ }^{\mathrm{c}}$

${ }^{a}$ National University of Uzbekistan named after Mirzo Ulugbek afakhriddinh@mail.ru

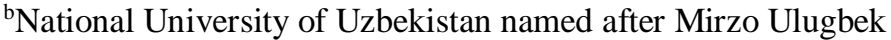

${ }^{\mathrm{c} S p e c i a l i z e d ~ s c h o o l ~ o f ~ U z b e k i s t a n ~ n a m e d ~ a f t e r ~ I b n-S i n o ~}$

cmirkhonova.zp@mail.ru

Key words: Hunting, hunting species of animals, hunting farms, hunting efficiency, animal ecology, Bukhara, poaching, water regime of reservoirs, recreation

\section{Abstract}

The wide and sometimes irrational use of the animal world for hunting and the existing problems in the management of hunting farms in many ways become the reason for the extinction or reduction of the number of species, and sometimes the animal becomes a rare or endangered species. The study of these issues and the development of recommendations for their solution is of scientific and practical importance in the protection and sustainable use of animals, optimizing the management of hunting farms and improving the economic and social wellbeing of violence.

\section{Introduction}

Wild animals in Uzbekistan, including in the Bukhara region, are used mainly for hunting purposes. In this region, there are currently only amateur hunting. More profitable commercial hunting developed only in 1960-1970. The conducted biotechnical activities and the management of hunting farms do not meet modern requirements. The profitability of hunting farms is currently at a low level. We have identified these problems hinder the development of hunting tourism and negatively affect the protection of hunting species of animals and their habitat. In the study, the species composition of the hunting species of the 
Bukhara region was determined, the environment of them identified the species that make up the basis of the animals that were harvested, the anthropogenic factors (barconry, animal husbandry, grazing of vegetation and others) and the degree of their impact on hunting species were determined. On the basis of mathematical calculation, the economic efficiency of hunting farms has been determined. Practical recommendations for solving problems related to the rational use and protection of hunting species of animals have been developed.

For each region, the species composition of animals belonging to hunting and the volume of their prey is different and this is due to the zoogeographic features and the specifics of hunting. Therefore, scientific approaches to compiling a list of hunting species and hunting management have scientific and practical importance in the aspect of rational use and protection of the animal world.

In Uzbekistan, hunting for 150 species of vertebrates (except for fish) is allowed. Of these, during the study period (2010-2019), 110 species were identified that are found in the Bukhara region (table 1).

Table 1

Taxonomic analysis of the fauna of game animals of the Bukhara region

\begin{tabular}{|l|l|l|l|}
\hline Classification & \multicolumn{1}{|c|}{ Divisions } & \multicolumn{1}{|c|}{ Family } & \multicolumn{1}{|c|}{$\begin{array}{c}\text { Number of } \\
\text { Species }\end{array}$} \\
\hline Amphibia & Anura & Ranidae & 1 \\
\hline \multirow{2}{*}{ Reptilia } & & Gekkonidae & 4 \\
\cline { 3 - 4 } & \multirow{3}{*}{ Squamata } & Lacertidae & 4 \\
\cline { 3 - 4 } & & Colubridae & 6 \\
\cline { 3 - 4 } & & Viperidae & 1 \\
\hline
\end{tabular}




\begin{tabular}{|c|c|c|c|}
\hline \multirow{14}{*}{ Aves } & Pelecaniformes & Phalacrocoracidae & 1 \\
\hline & Anseriformes & Anatidae & 19 \\
\hline & Galliformes & Phasianidae & 4 \\
\hline & Gruiformes & Rallidae & 3 \\
\hline & \multirow{6}{*}{ Charadriiformes } & Burhinidae & 1 \\
\hline & & Charadriidae & 13 \\
\hline & & Recurvirostridae & 2 \\
\hline & & Haematopodidae & 1 \\
\hline & & Scolopacidae & 21 \\
\hline & & Glareolidae & 2 \\
\hline & \multirow[t]{2}{*}{ Columbiformes } & Pteroclididae & 1 \\
\hline & & Columbidae & 3 \\
\hline & \multirow[t]{2}{*}{ Passeriformes } & Sturnidae & 3 \\
\hline & & Corvidae & 7 \\
\hline \multirow{6}{*}{ Mammalia } & Lagomorpha & Leporidae & 1 \\
\hline & \multirow{5}{*}{ Rodentia } & Sciuridae & 3 \\
\hline & & Myocastoridae & 1 \\
\hline & & Criceidae & 1 \\
\hline & & Canidae & 3 \\
\hline & & Mustelidae & 1 \\
\hline
\end{tabular}




\begin{tabular}{|l|l|l|l|}
\hline & Carnivora & Felidae & 2 \\
\cline { 2 - 4 } & Artiodactyla & Suidae & 1 \\
\hline Totally & 13 & 27 & 110 \\
\hline
\end{tabular}

Currently, there are 5 farms in the Bukhara region that are engaged in the production of animals. During the period of ecological research, it was revealed that in these hunting farms, the outward diversity of hunting species is almost the same, but the indicators of population density in the area are highly variable. This trend is explained by the same ecological location (the territories of all farms overlook the lakes and their coastal territories) of these farms, their area size and the degree of adherence to anthropogenic load.

Have been found that 13 species of animals are officially hunted in the hunting grounds of the Bukhara region (Sus scrofa, Meles meles, Lepus capensis, Vulpes vulpes, Canis aureus, Anser anser, Netta rufina, Aythya ferina, Anas platyrhynchos, Anas crecca, Fulica atra, Phalacrocorax carbo, Pterocles orientalis) and representatives of the reptile and amphibian classes are not found among them. It was found that illegal hunting is carried out for 11 species (Gazella subgutturoza, Canis lupus, Felis libyca, Ondatra zibethicus, Phasianus colchicus, Pterocles orientalis, Columba livia, Merops superciliosus, Eryx miliaris, Varanus griseus, Agrionemys horsfieldi). There are 4 types of environments (Gazella subgutturoza, Eryx miliaris, Varanus griseus, Agrionemys horsfieldi) included in the "Red Book" of Uzbekistan (2020). A significant amount of prey was noted in the class of birds (duck (6720), Fulica atra (1983), Anser anser (1978), on the contrary, the share of mammals in the volume of prey is very low (Sus scrofa, Vulpes vulpes $u$ Canis aureus) and is only 6-7 heads per year.

In terms of the average annual volume of animal production in the Karakyr hunting sector, it has a high rate $(6829 ; 48 \%)$, insignificant production $(447 ; 3 \%)$ is noted in the Karakul forest-hunting farm $\underset{w w w . g r p . g h g}{\text { fige }}$ ). 
This specificity of farms is explained by the ecological state of hunting farms, especially by fluctuations in the water regime of water bodies.

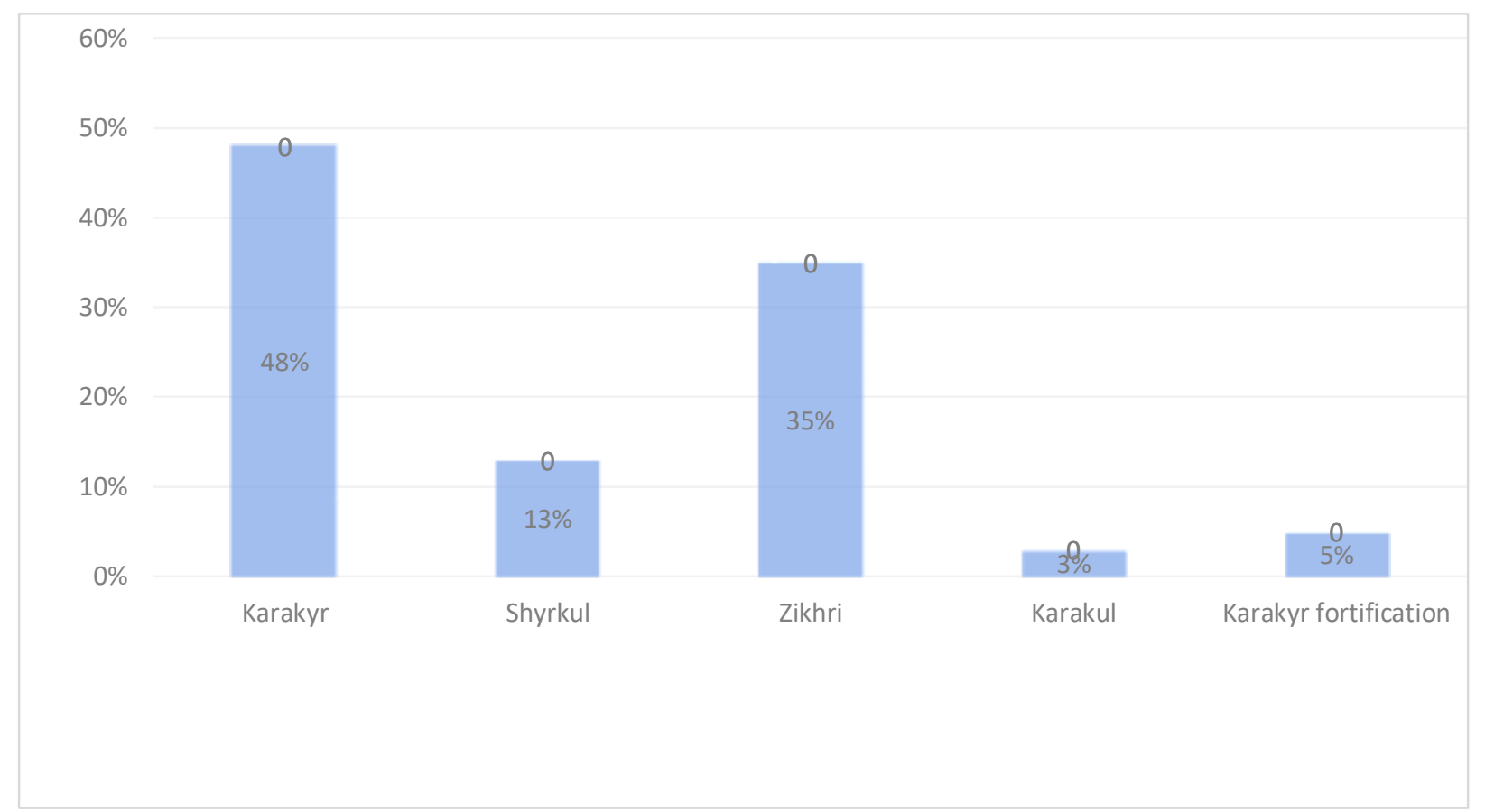

Figure 1: Average annual production of animals in the context of hunting farms (\%)

Have been identified and analyzed anthropogenic factors negatively affecting hunting species and their habitat. The degree of influence of the factor is determined in the scoring system, based on the study of their consequences (Table 2 ). In terms of the degree of impact, illegal hunting, vegetation grazing and livestock farming are the most negative factors.

Table 2

The degree of impact of anthropogenic factors on hunting species of animals

Views Types of anthropogenic factors and the degree of their impact (in points) 


\begin{tabular}{|c|c|c|c|c|c|c|c|c|}
\hline & 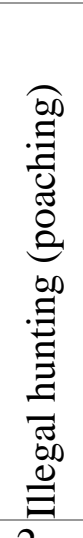 & 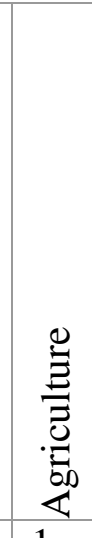 & 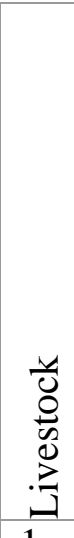 & 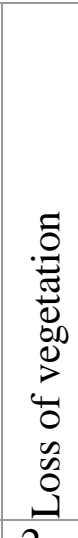 & 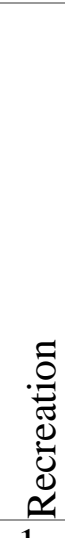 & 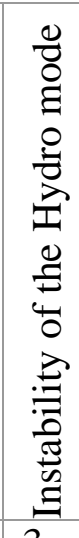 & 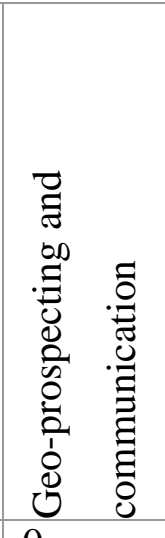 & 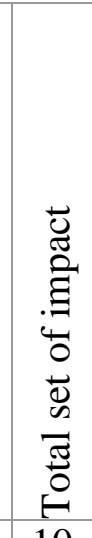 \\
\hline $\begin{array}{l}\text { Waterfowl } \\
\text { bird species }\end{array}$ & 2 & 1 & 1 & 2 & 1 & 3 & 0 & 10 \\
\hline $\begin{array}{l}\text { Pterocles } \\
\text { orientalis }\end{array}$ & 1 & 2 & 2 & 2 & 0 & 1 & 1 & 9 \\
\hline Sus scrofa & 3 & 0 & 2 & 3 & 1 & 2 & 1 & 11 \\
\hline Meles meles & 3 & 1 & 2 & 2 & 0 & 1 & 1 & 10 \\
\hline Lepus capensis & 1 & 1 & 3 & 3 & 0 & 0 & 2 & 10 \\
\hline Vulpes vulpes & 0 & 0 & 1 & 2 & 0 & 0 & 2 & 5 \\
\hline Canis aureus & 0 & 0 & 1 & 2 & 0 & 0 & 2 & 5 \\
\hline Felis libyca & 0 & 0 & 3 & 2 & 0 & 0 & 0 & 5 \\
\hline $\begin{array}{l}\text { Total set of } \\
\text { impact }\end{array}$ & 10 & 5 & 15 & 18 & 2 & 7 & 9 & \\
\hline
\end{tabular}

\section{Conclusions}

As a result of the review, have been developed the following recommendations:

- in hunting farms, conduct a biotechnical event aimed at restoring the number and reproduction of Sus scrofa and Meles meles;

- to hang the economic efficiency of hunting farms by creating appropriate conditions for the organization of hunting tourism; 
- regulate the abundance of Vulpes vulpes and Canis aureus to prevent their negative impacts on hunting species and the environment;

- by means of acclimatization of Myocastor coypus and Mustela lutreola, as well as an increase in the number of Ondatra zibethicus in hunting farms, to organize new hunts;

- public control is an effective tool for reducing the negative impact of anthropogenic factors on the territories of hunting farms;

Practical recommendations on the rational use of hunting species of animals, increasing the productivity and economic efficiency of hunting farms have been introduced into the practice of the Bukhara territorial branch of the Sports Association of Hunters and Fishers of Uzbekistan. The results contributed to the establishment of an acceptable quota for the capture of certain species, the organization of biotechnical measures aimed at improving the efficiency of the protection of hunting species. 


\section{Literature}

1. Kuzyakin V.A. Accounting for the number of hunting animals. - M .: Partnership of scientific publications KMK, 2017 .-- S. 84-250.

2. Yushkevich N.T., Motsny V.V. Forest hunting economy of the Negorelsky training and experimental forestry: state, problems, prospects // Proceedings of BSTU. Series 1, No. 2. - Belarus, 2018 .-- pp. 156-159.

3. Parsons, K. C. Managing Wetlands for Waterbirds: Integrated approaches / K.

C. Parsons, S. C. Brown, R. M. Erwin, H. A. Czech // Waterbirds. 2002. Vol. 25, Spec. Publ. 2. P. 1-4.

4. Kholboev F.R., Rakhmonov R.R., Rayimov A.R. The role of adaptive reactions of starling synantropization // Regional problems of ecology and wildlife protection: Materials of the All-Russian scientific conference. Ulan-Ude, 2019 .-- S. 167-169. 